DOI: $10.1515 /$ pts-2017-0006

PHYSICS

\title{
THE ANALYSIS OF NON-NEWTONIAN VIBRO-IMPACT PROCESSES IN TUBE CONSTRUCTIONS AND SYSTEMS WITH PARALLEL IMPACT PAIRS
}

\author{
V. L. Krupenin ${ }^{1}$, J. Viba ${ }^{2}$ \\ ${ }^{1}$ A. Blagonravov Institute of Machines Science (IMASH RAN) \\ 4 Maly Kharitonievskiy Per., Moscow, 101990, RUSSIA \\ e-mail: krupeninster@gmail.com \\ ${ }^{2}$ Riga Technical University \\ 1 Kalku Str., Riga, LV-1658, LATVIA \\ e-mail: Janis.Viba@rtu.lv
}

The present paper studies the problems of creation of techniques for the analysis of vibro-impact processes in systems with a large number of impact pairs. The used method of singularisation allows refusing from the ideas of the momentary impact and considering interaction hypotheses, which are more realistic than Newtonian ones. We consider the features of synchronous modes of movements of the clap type in systems with parallel impact elements as well as in tubes colliding with intermediate supports. Such modes are most dangerous in terms of the vibration wear of structural elements. The examples of calculation are given for specific designs.

Keywords: $2 N$-parametrical representation, calculation for tube constructions, degrees of freedoms, integral equation of nonlinear oscillations, interaction momentum, interaction time, non-momentary impact, periodic Green's function, singularisation, synchronous impact.

\section{INTRODUCTION}

The problem of modelling and analysis of non-Newtonian vibro-impact systems, where the forces of shock interaction are described by threshold nonlinearities, was discussed in [1]. Apparently, V. K. Astashev was the first to consider such problems [2]. Any threshold nonlinearity represents the hypothesis of the impact interaction. Having used the hypothesis of instantaneous impact interaction, the author of [3] proposed a method of singularisation, which allowed creating approximate solutions to the problems requiring consideration of the finite duration impact. Singularisation method, developed in [4], [5], consists in the following: at interaction the concept of impact in first approximation still remains Newtonian (elastic impact), 
but the obstacles are set not as fixed but "floating" depending on the time of interaction defined by the non-Newtonian impact hypothesis. Thus, it makes possible to take into account different characteristics of elastic loading during the impact of the interacting subsystems, as well as to consider more realistic models of the dispersion energy during interaction. These issues are discussed below.

\section{OPERATOR EQUATION OF MOTION}

We consider a periodic vibro-impact process in a mechanical system of the general type comprising $\mathrm{N}$ impact pairs. In the construction process, we use in some modified form the methods of time-frequency analysis of vibro-impact processes [1], [4]-[10] based on the record of the desired laws of motion using periodic Green's function of the interacting linear mechanical subsystems. As an example, we consider a linear scleronomous, stationary mechanical system with an arbitrary finite number $\left(N_{1}\right)$ of degrees of freedom. For simplicity reasons, we restrict ourselves to assumption being, in general terms, insignificant that each point of the system performs a one-dimensional movement along a certain axis. Let us suppose that a family of operators of dynamic compliance of the given system $L(u, y ; p)$, where $u$ and $y$ are its arbitrary points, is known. Each such operator associates a force applied in the point $u$ with the displacement of the point $y ; p \equiv d / d t$.

We suppose that at $N \leq N_{l}$ points $\left\{u_{\mathrm{k}}\right\}: L\left(u_{k}, u_{k}\right)=O\left(p^{-2}\right)(p \rightarrow \infty)$. This assumption means, in particular, that at points $\left\{u_{\mathrm{k}}\right\}$ some bodies with mass $m_{\mathrm{k}}$ are concentrated. We assume further that each such point contains an impact pair, which is supposed to be asymmetric and unilateral for definiteness, i.e., there is an ordered set of numbers $\left\{\Delta_{k}\right\}$ such that $u_{\mathrm{k}} \leq \Delta_{k}$ and at $u_{\mathrm{k}}=\Delta_{k}$ a direct and central non-Newtonian impact interaction takes place. We denote the impact force in the $k$-th pair as $\Phi_{\mathrm{k}}\left(u_{k} ; \dot{u}_{k}\right)$; we particularize the form of $\Phi_{k}\left(u_{k} ; \dot{u}_{k}\right)$ below. It is common to set $\Phi_{k}\left(u_{k} ; \dot{u}_{k}\right)=\Phi_{1 k}\left(u_{k}\right)+\Phi_{2 k}\left(u_{k} ; \dot{u}_{k}\right)$, where $\Phi_{1 k}\left(u_{k}\right)$ is an elastic component and $\Phi_{2 k}\left(u_{k} ; \dot{u}_{k}\right)$ is a dissipative one.

Assuming, finally, that periodic (with period $T_{0}$ ) external excitatory forces $P_{\mathrm{h}}\left(u_{h} ; \dot{u}_{h} ; t\right)$ are applied in some selected $H \leq N_{l}$ points $\left\{u_{h}\right\}$, we can write for the points $u_{\mathrm{k}}$ :

$$
u_{\mathrm{k}}(\mathrm{t})=\sum_{h=1}^{H} L\left(u_{\mathrm{k}}, u_{\mathrm{h}} ; \mathrm{p}\right) P_{\mathrm{h}}\left(u_{h} ; \dot{u}_{h} ; t\right)-\sum_{n=1}^{N} L\left(u_{\mathrm{k}}, u_{\mathrm{n}} ; \mathrm{p}\right) \Phi_{k}\left(\mathrm{u}_{\mathrm{k}} ; \dot{u}_{k} ; s\right) .
$$

We should also point out that similarly we can consider the case where concentrated bodies of the studied system collide among themselves [4].

Let us assume that the family $\left\{P_{\mathrm{h}}\right\}$ is $T$-periodic. To find the T-periodic laws of motion $u_{\mathrm{k}}(\mathrm{t})$, one can use a system of integral equations of the periodic fluctuations of Hammerstein type [4]-[7] when $k=1, \ldots, n$ :

$$
\begin{aligned}
& u_{\mathrm{k}}(\mathrm{t})=\sum_{h=1}^{H} \int_{0}^{T} \chi\left(u_{k}, u_{h} ; t-s\right) P_{\mathrm{h}}\left[u_{h}(s) ; \dot{u}_{h}(s) ; s\right] d s- \\
& -\sum_{n=1}^{N} \int_{0}^{T} \chi\left(u_{\mathrm{k}}, u_{n} ; t-s\right) \Phi_{k}\left[\mathrm{u}_{\mathrm{k}}(s) ; \dot{u}_{k}(s) ; s\right] d s .
\end{aligned}
$$


Here $\chi\left(u_{\mathrm{k}}, u_{\mathrm{h}} ; t-s\right)$ is a periodic Green's function (PGF) corresponding to the operator $L\left(u_{\mathrm{k}}, u_{\mathrm{h}} ; \mathrm{p}\right)$ :

$$
\chi\left(u_{\mathrm{k}}, u_{\mathrm{h}} ; t\right)=T^{-1} \sum_{q=-\infty}^{\infty} L\left(u_{\mathrm{k}}, u_{\mathrm{h}} ; i q \omega t\right) \exp (i q \omega t)
$$

PFG properties are described in detail in [4], [6]; they represent the response of linear systems to periodic sequence of Dirac $\delta$-functions (Dirac comb):

$$
\delta^{T}(t)=\sum_{n=-\infty}^{\infty} \delta(t-n T)=T^{-l} \sum_{q=-\infty}^{\infty} \exp (i q \omega t)
$$

The first term on the right side (4), thus, turns out to be the solution to the linear problem (all $\Phi_{k} \equiv 0$ ). If all the excitatory forces are symmetric and impact pairs are also symmetric, then in order to find the symmetric motion modes $u_{\mathrm{k}}(t)=-u_{\mathrm{k}}(t+T / 2)$ of the system (1) we can use symmetrizable integral equations (2), where the integration is taken in the interval $[0, T / 2]$, while symmetric PFG-s serve as kernels:

$$
\chi^{*}\left(u_{\mathrm{k}}, u_{\mathrm{h}} ; t\right)=2 T^{-1} \sum_{q=-\infty}^{\infty} L\left\{u_{\mathrm{k}}, u_{\mathrm{h}} ;[i(2 q+1) \omega t]\right\} \exp [i(2 q+1) \omega t],
$$

which proves to be a linear system response to a double Dirac comb:

$$
\delta^{\mathrm{T} / 2}(t)=\sum_{n=-\infty}^{\infty}\left[\delta(t-n T)-\delta(t-T / 2-n T)=T^{-l} \sum_{q=-\infty}^{\infty} \exp [i(2 q+1) \omega t] .\right.
$$

The representation of PFG-s is useful in their final form at intervals of periodicity (symmetry) - see [4], [6], [9] and below.

\section{HYPOTHESIS OF IMPACT}

In terms of collisions, we need to consider the hypothesis of an impact. We will initially assume that the impact is perfectly elastic and direct. Let us consider the so-called threshold functions from the class $\{\Phi\}_{\Delta}[1],[4],[5]$. We denote the threshold as a coordinate, after passing of which the impact interaction between two bodies or a body and a fixed limiter begins. The coordinate is counted along the axis of impact. If the impact is absolutely rigid and the deformation of colliding bodies can be neglected, then the duration of the impact is zero (momentary impact).

In the event of momentary impact, a well-known Newtonian hypothesis is applied. The impact force, in this case, is written using a singular generalized function [1], [3], [4], [6]. However, if it is important to take into account either finite duration of impact force or energy losses during the interaction, one should take into account some theories of contact damping based, for example, on the material properties of the interacting bodies, and here it is necessary to abandon assumptions about the momentary nature of the interaction.

First, let us consider an elastic impact. Generally speaking, the choice of 
hypothesis of impact is a problem of designation of representation of the interaction force. If an impact pair is one-sided and asymmetric as shown in Fig.1, then a responding threshold function $\Phi_{1}\left(u_{k}\right)=\lambda \Phi_{k}\left(u_{k}\right)$ is also asymmetric. In fact, with the help of this function, the hypothesis of the impact in this pair can be determined. Here $\lambda>>1$ is a large parameter. The class of threshold functions for a given task is defined as follows (Fig. 1):

$$
\begin{aligned}
& \Phi_{k} \in\{\Phi\}_{\Delta} \equiv \\
& \equiv\left\{\Phi_{k}\left(u_{k}\right) ; \Phi\left(u_{k}\right)=\psi_{k}\left(u_{k}-\Delta\right) \eta\left(u_{k}-\Delta\right), \Delta \geq 0 ; \psi_{k}\left(u_{k}-\Delta\right) \equiv 0 ; u_{k} \geq 0\right\} .
\end{aligned}
$$

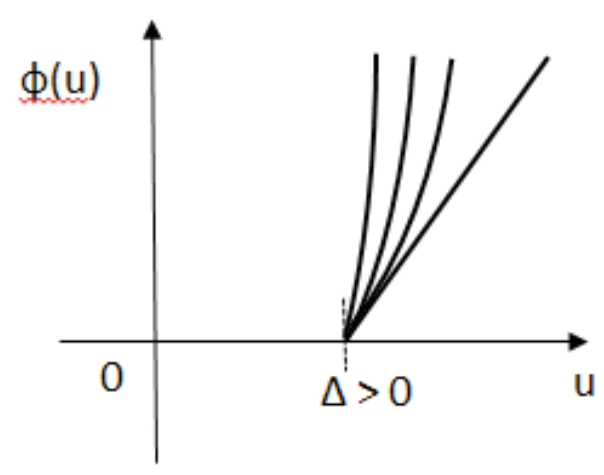

Fig. 1. One-sided and asymmetric impact pair. $\Phi(\mathrm{u})$ - threshold function; $\mathrm{u}$ - local displacement.

It is assumed that $\psi_{k}\left(u_{k}\right)$ is continuously differentiable on the entire number axis, is convex and monotonically increases at $x \geq 0 ; \eta(x)$ is a unit function.

Following the first works, this approach was later developed in the book [4], while for systems with multiple impact pairs - in [6]. We fix the hypothesis of elastic interaction in each impact pair in form (3) and consider problem (1) [(2)] using the method of singularisation.

\section{THE REPRESENTATIONS OF PERIODIC MODES}

We consider a conservative analogue of the system of operator equations of motion (1). For all $k$ and $h$ we put $P_{\mathrm{h}}=\Phi_{2 k}=\operatorname{Im} L\left(u_{\mathrm{n}} u_{\mathrm{q}} ; i \omega\right)=0$ for all points in the system. Then the equation of motion of a conservative system with the operator $L_{0}\left(u_{\mathrm{k}}, u_{\mathrm{n}} ; p\right)$ for all $k$ takes the form:

$$
u_{\mathrm{k}}=\sum_{n=1}^{N} L_{0}\left(u_{\mathrm{k}}, u_{\mathrm{n}} ; \mathrm{p}\right)\left[\lambda \Phi_{n}\left(u_{\mathrm{n}}\right)\right], k=1, \ldots, N .
$$

In order to find periodic modes of motion in a conservative system, we use the integral equation of nonlinear oscillations, which in this case takes the form: 


$$
\left.u_{\mathrm{k}}(\mathrm{t})=-\sum_{n=1}^{N} \int_{0}^{T} \chi\left(u_{\mathrm{k}}, u_{n} ; t-s\right)\right) \lambda \Phi_{n}\left[\mathrm{u}_{\mathrm{n}}(s)\right] d s, \mathrm{k}=1, \mathrm{~N} \text {. }
$$

Works [1], [4] under similar assumptions show that when $\lambda \rightarrow \infty$, the solutions of equations similar to (8) transform into the solutions that meet the hypothesis of a momentary (in this case elastic) impact.

It is postulated that during the interaction in arbitrary impact pair one can neglect the effect of any forces applied in the point of the pair localization, as well as of any forces, including interaction forces applied at other points of the system.

Let us use the method of singularisation that associates a non-momentary short interaction with a momentary impact, which takes place at a "shifted time". In accordance with the method, we can approximate the forces from equation (8) as a singular generalized function. In particular, for T-periodic process under the assumption of a single interaction for the period of movement in each impact pair:

$$
\lambda \Phi_{\mathrm{n}}\left[u_{\mathrm{n}}(t)\right]=J_{\lambda \mathrm{n}} \delta^{T}\left(t-t_{\mathrm{n}}-\tau_{\lambda \mathrm{n}}\right) ; \quad n=1, \ldots, N
$$

where $t_{\mathrm{n}}$ is a fixed moment of the beginning of interaction in the $n$-th impact pair (phase); furthermore, $t_{\mathrm{nk}} \in[0, T] ; \tau_{\lambda_{\mathrm{n}}}=\frac{1}{2} t_{\lambda_{\mathrm{n}}}$ - half time of interaction in this pair determined from the previously obtained formulas [10], [6], [11] (see also below).

Representation (9)-(10) is caused by the fact that, first, we find the modes of motion namely of periodic type in a conservative system, and, secondly, the forces of interaction, as in the case of hypothesis of momentary impact, are given by equations of motion containing singular generalized functions. Such equations of motion are called singularized. In formula (10), $J_{\lambda \mathrm{n}}$ is a momentum of interaction in each $n$-th impact pair:

$$
J_{\lambda \mathrm{n}}=\left|\int_{0}^{t} \lambda \Phi_{\mathrm{n}}\left[u_{\mathrm{n}}(s)\right] \mathrm{d} s\right|, k=1, \ldots, N .
$$

Now from (8) we obtain:

$$
u_{\mathrm{k}}(\mathrm{t})_{=}-\sum_{n=1}^{N} J_{\lambda_{\mathrm{n}}} \chi_{k n}\left(t-t_{\mathrm{n}}-\tau_{\lambda_{\mathrm{n}}}\right), \quad k=1, \ldots, N \text {. }
$$

Representation (12) determines the solution using $2 \mathrm{~N}$ parameters that are momenta of interaction and the moments of the beginning of interaction. As in problems with momentary impact, we will call such a solution as $2 \mathrm{~N}$ - parametric representation [6]. To find $N$ unknown motion parameters, we use the terms of the beginning (or the end) of the interaction:

$$
u_{\mathrm{k}}\left(t_{\mathrm{n}}\right) \equiv u_{\mathrm{k}}\left(t_{\mathrm{n}}+t_{\lambda \mathrm{n}}\right)=\Delta_{\mathrm{k},} \quad k=1, \ldots, N,
$$

where $\Delta_{\mathrm{k}}-$ the values of the installation clearance (preload) and

$$
\Delta_{\mathrm{k}}=\sum_{n=1}^{N} J_{\lambda_{\mathrm{n}}} \chi_{k n}\left(t_{\mathrm{n}}+\tau_{\lambda \mathrm{n}}\right) ; \quad k=1, \ldots, N .
$$


Relations (14) represent a system of $\mathrm{N}$ linear algebraic equations; the quantities $\tau_{\lambda \mathrm{n}}$ will be given below. Furthermore, $\mathrm{N}$ conditions for quantities $t_{\mathrm{n}}$ can be obtained from the additional relations resulted from (13) and concretized hypotheses of interaction. When addressing a conservative task, it is expedient to involve consideration of symmetry. To obtain analytical design equations, it is advisable to remain within the analytical design formulas, assume for all $k: \Delta_{\mathrm{k}} \equiv \Delta$. On the use of numerical methods in such systems, see [12].

\section{PERIODIC CLAPS IN THE ELASTIC CHAIN}

By a clap we mean a driving mode, in which all or a part of massive bodies move in-phase and interact synchronously, for example, with limiters. With a clap, the vibro-impact process turns out to be most intensive [8]. We consider a model system with periodic structure (Fig. 2) [8]-[10]. Let us consider an elastic model. So as not to limit generality, we assume, for simplicity, $m=c=1$. In addition, it is natural to assume that all impact pairs act under the same hypothesis of interaction.

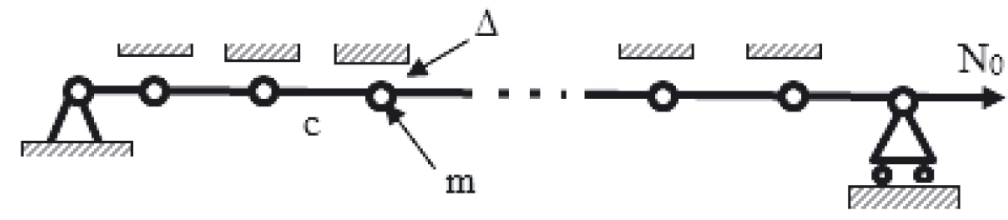

Fig. 2. Elastic model system with a periodic structure: $m$ - local mass; $\Delta$-gap.

Under the assumption of a conservative system, the equations of motion for $k=1, \ldots, N$ and boundary conditions take the form

$$
\ddot{u}_{k q}+2 u_{\mathrm{k}}-u_{\mathrm{k}-1}-u_{\mathrm{k}+1}+\lambda \Phi\left(u_{\mathrm{k}}\right)=0, u_{0}=u_{\mathrm{N}+1}=0,
$$

where $u_{\mathrm{k}} \leq \Delta$ and the clap, first, is assumed to be perfectly elastic (see below).

Let the system experience a clap in which all the particles take part. Then $2 N$-parametric representation (12) and defining relations (13), (14), when $k=1, \ldots, N$ and $t_{n}=0$, describe the clap, in which the beginning of the interaction is combined with the reference point of time. PFG system in this case is determined by a series (3), which, taking into account the representation of the operators of dynamic compliance given in [4], can be written in final form on an interval of periodicity for $t \in[0, T]:$

$$
\chi_{\mathrm{kn}}(t)=\sum_{q=1}^{N} \frac{1}{N+1} \sin \left(\frac{\pi j q}{N+1}\right) \sin \left(\frac{\pi k q}{N+1} \frac{\cos \left[\Omega_{q}(t-T / 2)\right]}{\Omega_{q} \sin \left(1 / 2 \Omega_{q} T\right)}\right),
$$

further, natural frequencies of the linear chain

$$
\Omega_{q}=2 \sin \left[\frac{\pi q}{2(n+1)}\right] .
$$


To obtain a finite representation for PFG $\chi_{k N}(\mathrm{t})$ outside the interval $[0, \mathrm{~T}]$, we have to extend the function (16) periodically, using the condition $\chi_{k n}(t)=\chi_{\mathrm{kn}}(t+T)$ for all $t \in \boldsymbol{R}$.

Formulas (12) and (14) contain the quantity $\tau_{\lambda_{n}}$ which is a half of the interaction time in the $n$-th impact pair.

Quantities $\tau_{\lambda \mathrm{nj}}$, generally speaking, depend on the selected hypotheses and impulse of interaction. Works [4]-[6] give the defining relations when choosing the hypothesis of interaction in form:

$$
\lambda \Phi_{\mathrm{n}}(x)=(x-\Delta)^{\alpha} \eta(x-\Delta), \alpha \geq 1 .
$$

In a common case of the hypothesis of linear dependence of the interaction force in the contact zone, i.e., when in (19) $\alpha=1$, it is shown that at a fixed parameter $\lambda$ and large momenta, the interaction time does not depend on the quantity of the latest and

$$
\tau_{\lambda n}=\pi / 2 \sqrt{\lambda}
$$

so, by choosing this hypothesis (18), in representation (12) for all $n$ we can assume $\tau_{\lambda n} \equiv \tau_{\lambda}=\operatorname{const}\left(J_{\lambda}\right)$. In this case $m=1$.

While abandoning the assumption that the momenta of interaction are large, the interaction becomes dependent but this dependence is rather weak. When $\alpha>1$ (always $\tau_{\lambda n} \equiv \tau_{\lambda} \neq \operatorname{const}\left(J_{\lambda}\right)$ ), for large momenta, this dependence is weak. Expressions for the parameters of singularitarian equations and representations of movement when $\alpha>1$ are not given here, as they are not used further; see [4]-[6]. Note that the interaction time $\sim \tau_{\lambda}$ can also be taken from experimental data.

\section{EXAMPLE: A THREE-SPAN CHAIN}

Consider a three-span chain $(N=2)$. From (14) it follows:

$$
\Delta=J_{1} \chi_{11}\left(\tau_{\lambda}\right)+J_{2} \chi_{12}\left(\tau_{\lambda}\right) ; \Delta=J_{1} \chi, 21\left(\tau_{\lambda}\right)+J_{2} \chi_{22}\left(\tau_{\lambda}\right) .
$$

As $\chi_{11}\left(\tau_{\lambda}\right)=\chi_{22}\left(\tau_{\lambda}\right)$ and $\chi_{12}\left(\tau_{\lambda}\right)=\chi_{, 21}\left(\tau_{\lambda}\right)$, then $J_{1}=J_{2}=J$. For natural frequencies we find from (17): $\Omega_{1}=1, \Omega_{2}=\sqrt{3}$.

The quantity of $J$ uniquely depends on the total energy and appears to be the integral of motion. Another integral of motion is arbitrary moment of the interaction beginning [4]-[7].

Thus, from formula (14) we obtain an approximate representation of the solution $(\mathrm{m}=1)$ :

$$
u_{1}(t)=u_{2}(t) \equiv u(t)=J\left[\chi_{11}(t-\pi / 2 \sqrt{\lambda})+\chi_{12}(t-\pi / 2 \sqrt{\lambda})\right] .
$$

For example, from the first equation (18), considering (20) and (22), we find for large momenta of the interaction: 


$$
J=\Delta\left[\chi_{11}(\pi / 2 \sqrt{\lambda})+\chi_{, 12}(\pi / 2 \sqrt{\lambda})\right]^{-1} .
$$

Given PFG properties [4] inside the interval of periodicity and using the Taylor's formula we write: $\chi_{\mathrm{kq}}\left(\tau_{\lambda}\right) \approx \chi_{\mathrm{kq}, \mathrm{nj}}(0)+\pi / 4 \sqrt{\lambda} \ldots$. Then formula $(23)$ can be
represented as follows:

$$
J \approx \Delta\left[\chi_{11}(0)+\chi_{12}(0)+\pi / 4 \sqrt{\lambda}\right]^{-1} \approx J_{0}-\pi / 4 \sqrt{\lambda},
$$

where $J_{0}$ is the momentum of the interaction at the synchronous clap under the assumption that the hypothesis of momentary impact takes place $(\lambda \rightarrow \infty)$. As

$$
\begin{aligned}
& \chi_{11}(0)=\chi_{22}(0)=\frac{1}{3}\left(\frac{3}{4} \operatorname{ctg} \frac{1}{2} T+\frac{\sqrt{3}}{4} \operatorname{ctg} \frac{\sqrt{3}}{2} T\right) ; \\
& \chi_{12}(0)=\chi_{21}(0)=\frac{1}{3}\left(\frac{3}{4} \operatorname{ctg} \frac{1}{2} T-\frac{\sqrt{3}}{4} \operatorname{ctg} \frac{\sqrt{3}}{2} T\right),
\end{aligned}
$$

in an approximation of momentary impact:

$$
J_{0}=-2 \Delta \operatorname{tg} \frac{1}{2} T=-2 \Delta \operatorname{tg} \frac{\pi}{\varpi} .
$$

This formula exactly corresponds to the representation for the traditional "impact oscillator" [4], [8]. From the condition $\mathrm{j} \geq 0$, it follows that the claps are possible in the frequency range $1<\Omega_{\lambda} \leq \omega<2$, further $\Omega_{\lambda}=O\left(\lambda^{-1 / 2}\right)$. Given the performed calculations, from (21) for laws of motion we obtain:

$$
u(t)=\Delta \frac{\cos \left(t-\pi / 2 \sqrt{\lambda}-\pi \omega^{-1}\right)}{\cos \left(\pi \omega^{-1}\right)} ; \pi / 2 \sqrt{\lambda}<t<T-\pi / 2 \sqrt{\lambda},
$$

i.e., the motion of each body is similar to the motion of singularitariased impact oscillator. For large $\mathrm{N}$ the picture becomes slightly more complicated, because the claps are accompanied by unequal momenta in impact pairs.

Representation (23) appears to be most accurate for large values of the momentum, i.e., it presumes being close to the frequency $\omega=2$.

It is shown that in the case of three bodies, the momentum of the impact of the central body is somewhat larger than the momenta of the lateral bodies. In the case of four bodies, two central and two lateral ones, the momenta are pairwise equal, and so on. The dependence of $J(\omega)$ is given in [4].

\section{RESONANT MODES IN A THREE-SPAN CHAIN}

Let us consider the equation of motion (15), assuming that at the interaction in the contact zone the bodies are subjected to equal dissipative forces $\mathrm{g}\left(\dot{u}_{k}\right)$. Let us assume, in addition, that during the motion the interacting bodies are subjected to a force of viscous friction that depends on the absolute velocities of the bodies. Then, assuming the excited oscillation to be sinusoidal with frequency $\omega_{0}$, instead of (15) we obtain (in the case studied here $\mathrm{N}=2 ; u_{0}=u_{\mathrm{N}+1}=0$ ): 


$$
\ddot{u}_{k}+2 u_{\mathrm{k}}-u_{\mathrm{k}-1}-u_{\mathrm{k}+1}+\lambda \Phi\left(u_{\mathrm{k}}\right)=-\mathrm{g}\left(\dot{u}_{k}\right) \eta\left(u_{k}-\Delta\right)-2 \varepsilon b \dot{u}_{k}+\varepsilon P_{\mathrm{k}} \cos \left(\omega_{0} t+\varphi_{\mathrm{k}}\right) .
$$

Analysing the problem of finding of periodic modes of frequency $\omega_{0}$ in the system (27), we restrict ourselves to in-phase resonant modes, by which we imply the motions similar to the above-mentioned periodic modes of the correspondent conservative system. Let us assume that the levels of forces of excitation and dissipation are low, so that at the resonant modes a mutual compensation of their work takes place. We see such understanding of resonance in [4]-[11], in particular.

Let us consider the basic resonance modes. The frequencies $\omega_{0}\left(1<\Omega_{\lambda} \leq \omega_{0}<2\right)$ lie in the interval of existence of simultaneous claps. Let us assume that all external effects $P_{\mathrm{k}}(t)=\mathrm{e} P_{\mathrm{k}} \cos \left(\omega_{0} t+\varphi_{\mathrm{k}}\right)$ are in-phase and of equal amplitudes, i.e., for all $\varphi_{k}=\varphi ; P_{k}=P$. Let us denote the modes of the conservative system (15) at $\omega=\omega_{0}$ as $u^{(0)}$ $\left(\omega_{0} ; t\right)$. Thus, in this case for all $k$ we approximately assume:

$$
u_{\mathrm{kq}}(t) \approx u^{(0)}\left(\omega_{0} ; t\right)
$$

In the studied case $\mathrm{N}=2$. Therefore, the impulses of the interaction for both impact pairs are equal; at the increasing number $\mathrm{N}$ the form of the equation given below appears to be more complicated.

The momentum of the interaction $J^{(0)}\left(\omega_{0}\right)$ is given using the second relation (23) with $\omega=\omega_{0}$. The assumption made above about large momenta, leading to the simplification of the expression for the time of interaction, is consistent with the view of the resonant nature of the movement.

Considering that the beginning of the interaction coincides with the beginning of the zero time, we assume that the phase $\varphi$ is unknown. To find the phase, we write the equation of the balance of the works of non-conservative forces for motion

$$
\begin{aligned}
& \dot{u}^{(0)}\left(\omega_{0} ; t\right) \text { for the period } T_{0:} \\
& \int_{0}^{T_{0}}\left\{\mathrm{~g}\left[\dot{u}^{(0)}(t)\right] \eta\left(\dot{u}^{(0)}-\Delta\right)+2 \varepsilon b \dot{u}^{(0)}(t)-\varepsilon P \cos \left(\omega_{0} t+\varphi\right)\right\} \dot{u}^{(0)}\left(\omega_{0} ; t\right) d t=0 .
\end{aligned}
$$

Strictly speaking, this ratio should be written for all coordinates $u_{k}$. After transformation and computing of the number of quadrature, and being given the notation introduced in equation (28), we find:

$$
\begin{aligned}
& E_{c}\left[g ; J^{(0)}\left(\omega_{0}\right) ; \tau_{\lambda}\right]+\frac{\varepsilon b}{\sin ^{2}\left(1 / 2 \Omega T_{0}\right)} J^{(0)}\left(\omega_{0}\right)\left(1-\frac{\sin \left(\Omega T_{0}\right)}{\Omega T_{0}}\right)= \\
& =\frac{2 \omega_{0}^{2} P \sin \left[\omega_{0}\left(\varphi+\tau_{\lambda}\right)\right]}{\pi\left(\omega_{0}{ }^{2}-\Omega^{2}\right)} .
\end{aligned}
$$

Here $E_{c}\left[g ; J^{(0)}\left(\omega_{0}\right) ; \tau_{\lambda}\right]$ is the energy loss during contact. It should be noted that as the force $\Phi_{2}\left(u_{k} ; \dot{u}_{k}\right)$ acts in a short time $\tau_{\lambda} \sim \lambda^{-1 / 2}$, in order to account this force in the present approach, we should consider $\Phi_{2} \sim 1$. From equation (30) we define 
two quantities of phase, one of which corresponds to the unstable mode as well as to the condition of the resonant mode existence: $\left|\sin \left[\omega\left(\varphi+\tau_{\lambda}\right)\right] \leq 1\right|$. Thus, we have:

$$
\left|\frac{\pi\left(\omega^{2}-\Omega^{2}\right)}{2 P \omega_{0}^{2}}\left[E_{c}\left[g ; J^{(0)}\left(\omega_{0}\right) ; \tau_{\lambda}\right]+\frac{\varepsilon b}{\sin ^{2}\left(1 / 2 \Omega T_{0}\right)} J^{(0)}\left(\omega_{0}\right)\left(1-\frac{\sin \left(\Omega T_{0}\right)}{\Omega T_{0}}\right)\right]\right| \leq 1 .
$$

The driving modes of the clap type were registered experimentally and studied quite extensively [4], [8]-[11].

\section{CALCULATION OF PIPE VIBRO-IMPACT SYSTEM}

In heat exchanger pipes of power equipment, wear of tubes occurs due to continuous collisions with elements of spacer grids [13]. Periodic (in particular, sine wave) excitation of pipe vibration is conditioned by the unsteadiness of fluid flow, impinging on the pipe with velocity $v$. Let us consider the system presented in Fig. 3. A simply supported rod simulating a pipe at oscillations in the plane $(u, x)$ can interact with $\boldsymbol{n}$ flat extended with limiters $h_{\mathrm{j}}(j=1,2, \ldots, N)$. Parameters of the system are: rod length $1>>$ hj; tensile force $N_{0}$, the rigidity and linear mass of the $\operatorname{rod} K$ and $\rho$, respectively; adjusting clearances $\Delta_{j 1,2}$; coordinates of the beginning and the end of the limiters $x_{j}$ and $\mathrm{x}_{\mathrm{j}}+\mathrm{h}_{\mathrm{j}}$, respectively. We consider a symmetric system and assume: $\Delta_{j 1}=\Delta_{j 2} \equiv \Delta$. In order to take into account the finite duration of impact, let us assume that the interaction occurs in elastic-dissipative buffers equipped with a dry friction damper, i.e., the interaction corresponds to some hysteresis characteristic.

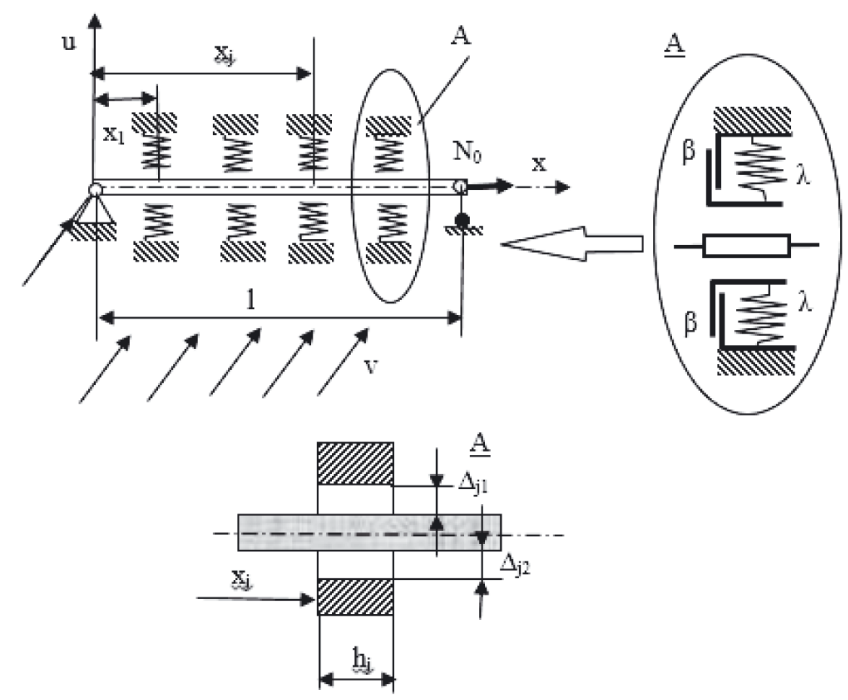

Fig. 3. A simply supported rod simulating a pipe at oscillations in the plane $(u, x)$.

Assuming that small dissipation is taken into account only at interaction and in the case the level of excitation is low, we write the equation of motion under the assumption that the rod is modelled by the Bernoulli beam

$$
\rho u_{\mathrm{tt}}+K u_{4 \mathrm{x}}-N_{0} u_{\mathrm{xx}}+\lambda \Phi^{*}(u)=\varepsilon P(x, t)-\beta \operatorname{sign} u_{\mathrm{t}}[\eta(u-\Delta)-\eta(u+\Delta)] .
$$


Let the boundary conditions correspond to simple support: $u(0, t)=$

$=\mathrm{u}(l, t)=u_{\mathrm{xx}}(0, t)=u_{\mathrm{xx}}(l, t)=0 ; \varepsilon=\mathrm{O}\left(\lambda^{-1 / 2}\right)-$ a small parameter; quantities $h_{j} \sim \varepsilon ; \mathrm{b} \sim 1 ; T_{0}-$ a periodic external excitement.

Let us suppose that the symmetric elastic force of the interaction is described by a function from the class of symmetric threshold functions: $\Phi^{*} \in\left\{\Phi^{*}\right\}_{\Delta}-[4]$.

At first, let us assume that $\varepsilon=\beta=0$ and consider a conservative model. Let us assume that in the system free periodic fluctuations settle. Then, in definitory relations in Section 4 and below we turn to the density of the parameters and record the density of the elastic impact forces acting at $x \in\left[x_{\mathrm{k}}, x_{\mathrm{k}}+h_{\mathrm{k}}\right]$ through the density of the impact momentum $I(x)$, the phase distribution $\varphi(x)$ and the distribution of the interaction time $\tau_{\lambda}(x)[15]$

$$
\lambda \Phi^{*}[u(x, t)]=\sum_{k=1}^{N} I(x) \delta^{T / 2}\left[t-\varphi(x)-\tau_{\lambda}(x)\right]\left[\eta\left(x_{k}\right)-\eta\left(x_{k}+h_{k}\right)\right],
$$

where a double Dirac comb $\delta^{T / 2}$ is given in (6). Therefore, for the searched displacement field an integral representation, analogous to the $2 \mathrm{~N}$-parametric representation (12) [7], holds:

$$
u(x, T)=, u(x, t)=-\sum_{n=1}^{N} \int_{x_{k}}^{x_{k}+h_{k}} \chi^{*}\left[x, z, t-\varphi_{k}(z)-\tau_{\lambda k}(z)\right] I_{k}(z) d z
$$

where $\varphi_{k}(z), \tau_{\lambda k}(z), I_{k}(z)$ are the corresponding distributions in $k$-th impact element. Symmetric PFG for the beam for $0 \leq t \leq T / 2$ has the form [4], [5]:

$$
\begin{aligned}
& \chi^{*}(x, z, t)= \\
& =\frac{1}{\rho l} \sum_{n=1}^{\infty}\left[\Omega_{n} \cos \left(1 / 4 \Omega_{n} T\right)\right]^{-1} \sin \left(\pi n x l^{-1}\right) \sin \left(\pi n z l^{-1}\right) \sin \left[\Omega_{n}(t-1 / 4 T)\right] .
\end{aligned}
$$

It also corresponds to the operator of dynamic compliance, which acts from point $z$ to point $x$. The natural frequencies of the linear system are $\Omega_{n}=\left(\pi^{4} n^{4} K \rho^{-1} l^{-4}+\pi^{2} n^{2} N_{0} \rho^{-1} l^{-2}\right)^{1 / 2}$. Outside the interval [0, T/2], function (34) is extended on the whole axis in terms of frequency, based on conditions of symmetry.

We will use the fact that the values $h_{\mathrm{k}}$ are small and the dynamic processes in the impact element itself have little influence on the settling regime. Furthermore, the interaction time, obviously, in all impact elements can be taken constant:

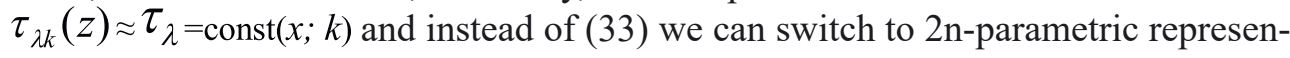
tation in the form

$$
u(x, t)=-\sum_{k=1}^{N} J_{\lambda k} \bar{\chi}^{*}\left(x, x_{k} ; h_{k} ; t-\varphi_{k}-\tau_{\lambda}\right) d z ; J_{\lambda \mathrm{k}}=\int_{x_{k}}^{x_{k}+h_{k}} I_{k}(z) d z=\operatorname{const}(x),
$$

where $J_{\lambda \mathrm{k}}$ - the full momenta in the $k$-th element.

Representation (35) also contains PFG $\bar{\chi}^{*}$ being averaged over the small length of the impact element: 


$$
\begin{aligned}
& \bar{\chi}^{*}\left(x, x_{k} ; h_{k} ; t\right)=h_{k}^{-1} \int_{x_{k}}^{x_{k}+h_{k}} \chi^{*}(x, z, t) d z= \\
& =-\frac{2}{\pi \rho h_{k}} \sum_{n=1}^{\infty} \frac{\sin \left(\pi n x l^{-1}\right) \sin \left[\pi n\left(x+1 / 2 h_{k}\right) l^{-1}\right] \sin \left(1 / 2 \pi n h_{k} l^{-1}\right) \sin \left[\Omega_{n}(t-1 / 4 T)\right]}{n \Omega_{n} \cos \left(1 / 4 \Omega_{n} T\right)} .
\end{aligned}
$$

Representation (35) is quite similar to (12). It implies that the mass of the reduced point contacting body $m_{\mathrm{k}}=\rho h_{\mathrm{k}}$, while the momenta $J_{\mathrm{k}}$ can be found from the system that follows from representation (35) and from the additional conditions, such as conditions of in-phase beginning of the interactions in all impact pairs of shock or other allowable additional conditions. For in-phase motions, we obtain (compare with (14))

$$
\Delta_{\mathrm{j}}=-\sum_{k=1}^{N} J_{\lambda_{\mathrm{n}}} \bar{\chi}^{*}\left(x_{j}, x_{k} ; h_{k} ; \tau_{\lambda k}\right) ; j=1, \ldots, N .
$$

Now, assuming that during the implementation of resonant condition the mode of movement approximately corresponds to a motion in a conservative system, we find the condition of existence of resonant modes based on the principle of energy balance, whereby the works of non-conservative forces are balanced on periodic motion.

In the conservative case, period T is a function of $J_{\lambda \mathrm{n}}(n=1, \ldots, N)$. Further, when examining single-frequency resonant modes, we assume that the period of the exciting effect is among the possible periods of oscillation of a conservative system $T_{0}=T$.

It should also be noted that in the practical use of singularized representations of type (35), we can use the estimated quantities obtained empirically and do not resort to calculations arising from the representation of power $\lambda \Phi^{*}[u(x, t)]$, on the basis of which the values of $\tau_{\lambda k}$ should be calculated.

\section{A THREE-SPAN TUBE}

Let us consider a three-span tube $(N=2)$ modelled through Bernoulli beams.

Let us assume that $h_{1}=h_{2} \equiv h ; \Delta_{1}=\Delta_{2} \equiv \Delta ; x_{2}=l-x_{1}-h$. Solving system (24) and denoting the frequency of free oscillations, from system of equations (35) we find: $J_{\lambda 1}=J_{\lambda 2} \equiv J_{\lambda}$, where:

$$
\begin{aligned}
& J_{\lambda}= \\
& =\frac{1}{4} \pi \rho \Delta h\left\{\sum_{j=1}^{\infty} \frac{\sin \left[\rho(2 j-1) x_{1} l^{-1}\right] \sin \left[1 / 2 \pi(2 j-1) h l^{-1}\right] \sin \left[\pi(2 j-1) l^{-1}\left(x_{1}+h / 2\right)\right]}{(2 j-1) \Omega_{2 j-1} \cos \left(1 / 2 \Omega_{2 j-1} \pi \omega\right)\left[\sin \Omega_{2 j-1}\left(\tau_{\lambda}-\pi / 2 \omega\right)\right]^{-1}}\right\}^{-1},
\end{aligned}
$$

moreover, this entry holds only when $\tau_{\lambda} \in\left[0, \pi \omega^{-1}\right]$. Formula (37) together with (35) describes the claps with alternate interaction with the limiters in a conservative 
system. Equating to zero brace (27), it is possible to find the frequency corresponding to the infinite pulses, i.e., the frequencies of maximum vibration wear.

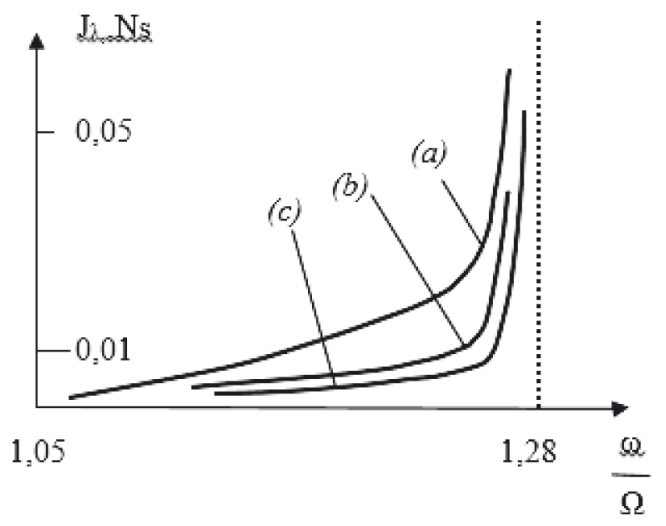

Fig. 4. Results of experimentally observed claps. Curves $(a),(b)$ and $(c)$ correspond to the cases $x_{1}=0.7,0.85$ and 1 , respectively.

Let us perform calculations using the following geometrical and physical characteristics of round tube [15]: the outer and inner diameters $D=16.10^{-3}$ and $d=$ $13.10^{-3} \mathrm{~m}$, respectively, Young's modulus $\mathrm{E}=2 \cdot 10^{11} \mathrm{~N} \cdot \mathrm{M}^{-2}$, whence it follows that $K=1 / 64 \pi \mathrm{E}\left(D^{4}-d^{4}\right)=363 \mathrm{~N} \cdot \mathrm{M}^{-2}$; tube length $l=3 \mathrm{M}, \rho=1.1 \mathrm{kG} / \mathrm{M}, N_{0}=4 \cdot 10^{3} \mathrm{H}, h=10^{-2} \mathrm{M}$, $\tau_{\lambda}=510^{-4} \mathrm{c}$.

The frequency zones, where the modes of motion of clap type may exist formally, are defined by the condition $J_{\lambda} \geq 0$. In order to find their boundaries, it is necessary to determine the frequencies at which $J_{\lambda}=0$ и $J_{\lambda} \rightarrow \infty$.

Numerical calculations reveal that one such zone exists on the right of the first natural frequency of the linear system and occupies the interval $\left[1.05 \Omega_{1}, 1.28 \Omega_{1}\right]$. The calculations took account of 22 terms of the series (37). Verification of convergence was carried out numerically. Along with the specified zone, the others were identified, which turned out to be very narrow. Consideration of them in this case makes no practical sense. The observation made is in agreement with the experiment [10], [11].

We restrict our consideration to experimentally observed claps - the modes, settling to the right of the first natural frequency of the linear system. This makes possible to obtain the dependences shown in Fig. 4 (curves $(a),(b)$ and $(c)$ correspond to the cases $x_{1}=0.7,0.85$ and 1 , respectively).

Let $P(x, t)=P_{1} \sin \left(\pi x l^{-1}\right) \cos \left(\omega_{0} t+\varphi\right)$ in equation (31). We consider the forced resonant oscillations of the synchronous type, which can only be carried out in case the frequency $\omega_{0}$ belongs to the interval of natural frequencies $\left[1.05 \Omega_{1}\right.$, $1.28 \Omega_{1}$ ]. We describe the movement through (35)-(37), (39), assuming, as noted above, that the studied regime is close to the regime of free vibrations $u^{(0}$ and $\omega_{0}=\omega$ : $u(x, t) \approx u^{(0)}\left(J_{\lambda} ; x, \mathrm{t}\right)+\ldots$, where the momentum $J_{\lambda}$ is given by formula (37).

Aligning the impact with the zero time, we assume that the phase $\varphi$ is unknown. To find it, we will use the principle of energy balance [see (31)], which in this case can be written for the half-period: 


$$
\begin{aligned}
& \int_{0}^{l T} \int_{0}^{T / 2} P_{1} \sin \left(\pi x l^{-1}\right) \cos \left(\omega_{0} t+\varphi\right) u_{\mathrm{t}}{ }^{(0)}\left(x, t-\tau_{\lambda}\right) d t= \\
& =\int_{0}^{l T / 2} \int_{0} \beta \operatorname{sign} u_{\mathrm{t}}{ }^{(0)}\left[\eta\left(u^{(0)}-\Delta\right)-\eta\left(u^{(0)}+\Delta\right)\right] u_{\mathrm{t}}{ }^{(0)}\left(x, t-\tau_{\lambda}\right) d t,
\end{aligned}
$$

where the left part of the equation contains the work of external source force on the motion $u^{(0)}(x, \mathrm{t})\left(T=T_{0}\right)$; with the expression for energy loss in the interaction [see (32)] being in the right part. Equation (38), given the correlations, enables us to obtain the condition of the existence of the resonant mode $\left(\left|\sin \left(\varphi+\tau_{\lambda}\right)\right| \leq 1 \mid\right)$ :

$$
P_{1} \geq\left|\frac{E_{c}\left[\beta ; J^{(0)}\left(\omega_{0}\right) ; \tau_{\lambda} ; h ; x_{1}\right] \pi\left(\Omega_{1}^{2}-\omega^{2}+\alpha\right)}{4 l \omega \sin (\pi h / 2 l) \sin \left[\pi / l\left(x_{1}+0,5 h\right)\right]}\right| ; \alpha=O\left(\lambda^{-1 / 2}\right) .
$$

Here the incoming quantity $E_{c}\left[\beta ; J^{(0)}\left(\omega_{0}\right) ; \tau_{\lambda} ; h ; x_{1}\right]$ in accordance with the structure of the right side of (38) determines the energy loss during the interaction. We similarly analyse an asymmetric case as well as other types of movement settling in such systems.

An overview of the issues discussed here is available in [14], [15].

\section{ACKNOWLEDGEMENTS}

The authors are grateful to V.K Astashev and M. G. Zhizhchenko for valuable comments.

The present research has been supported by the Russian Science Foundation under grant No. 15-19-30026.

\section{REFERENCES}

1. Krupenin, V.L. (1983). Vibration of the systems with large threshold elastic forces. $M e-$ chanics of Solids, 4, 76-84.

2. Astashev, V. K. (1965). Periodic Motion of an Elastic Rod with Limiters. The Dynamics of Machines with Given the Elasticity and Masses Variability. Moscow: Nauka.

3. Krupenin, V.L (1984). Calculation of mechanisms with threshold nonlinearities by a singularisation method. Mashinovedenie, 1, 6-12. (In Russian).

4. Babitsky, V.I., \& Krupenin, V.L. (2001). Vibration of Strongly Nonlinear Discontinuous Systems. Berlin: Springer-Verlag.

5. Krupenin, V.L (2014). Vibroimpulsive processes in the family of elastic systems with boundary elements interacting through non-Newtonian impacts. Journal of Machinery Manufacture and Reliability, 43(4). 261-269. DOI: 10.3103/S1052618814040098.

6. Krupenin, V.L (2010). The representation of periodic vibration-impact processes via pulse-phase motion parameters. Journal of Machinery Manufacture and Reliability, 39(1), 28-34. DOI: 10.3103/S1052618810010048. 
7. Krupenin, V.L. (2006). Calculation of vibration processes in two-dimensional lattices. Journal of Machinery Manufacture and Reliability, 4, 26-34.

8. Astashev, V.K., \& Krupenin, V.L. (1998). Waves in distributed and discrete vibroimpact systems and in strongly non-linear mediums. Journal of Machinery Manufacture and Reliability, 5, 13-30.

9. Krupenin, V.L. (1998). Vibro-impact processes in systems with large number impact pairs and distributed impact elements. In Dynamics of Vibro-Impact Systems. Euromech Colloquium 386, 15-18 September 1998. England: Loughborough University.

10. Babitsky, V.I., Krupenin, V.L., \& Veprik, A.M. (1988). Vibroimpact phenomena due to limited oscillations of one-dimensional elasto-connected particles. Dokl. AN USSR (Proc. USSR Academy of Sciences), 3(3), 562-566.

11. Astashev, V.K., Krupenin, V.L., \& Tresvyatskii, A.H. (1996). Experimental study of impacts synchronization in distributed systems with a variable number of impacts. Journal of Machinery Manufacture and Reliability, 2, 96-101.

12. Viba, J., \& Lavendelis, E. (2006). Algorithm of synthesis of strongly non-linear mechanical systems. In Industrial Engineering - Innovation as Competitive Edge for SME, 22 April 2006 (pp. 95-98). Tallinn, Estonia.

13. Krupenin, V.L. (2011). Representation of vibro-impact processes by physical parameters defining the movement "momentum - phase", Part II: Calculation of beam and tubular structures. Bulletin of Scientific and Technological Development, 10(50), 25-30.

14. Ibrahim, R.A. (2009). Vibro-Impact Dynamics. Berlin: Springer-Verlag.

15. Luo, A.C.J., \& Guo, Y. (2013). Vibro-Impact Dynamics. Chichester, West Sussex, UK: A John Wiley \& Sons, Ltd.

\title{
NE N̦ŪTONA VIBROTRIECIENA PROCESU ANALĪZE CAURULUU KON̉STRUKCIJĀS UN PARALĒLU TRIECIENA PĀRU SISTĒMĀ'S
}

\author{
V. L. Krupenin, J. A. Vība \\ Kopsavilkums
}

Šajā rakstā ir izpētīta iespēja radīt jaunu teoriju tādu vibro trieciena sistēmu analīzē, kurās ir liels skaits sadursmju pāru.

Izmantotā metode (ar singularitāti) atļauj atteikties no idejas par īslaicīgu objektu sadursmi un izvērtēt tam nolūkam jaunu mijiedarbības hipotēzi, kas ir tuvāka īstenībai, nekā N̦ūtona metode. Rakstā izmantotās funkcijas apraksta sinhronas sadursmes kustības "plaukškināšanas" veidā sistēmās ar paralēliem trieciena pāriem, kā arī caurules sadursmēs ar starpposmu balstiem. Šādi sadursmju režīmi no vibrācijām ir visbīstamākie konstrukciju elementos to nodilumu ziṇā. Doti aprēḳināšanas piemēri no reālajām konstrukcijām.

23.08.2016. 